\title{
Kuaishou short video social network from the perspective of urban-rural cultural linkage: a field study on the mobile internet practices of young Monguor villagers in China's Qinghai Province
}

\section{Guangxu Ji ${ }^{1} \mathbb{D}$}

Received: 25 March 2021 / Accepted: 5 June 2021 / Published online: 19 July 2021

(c) The Author(s). 2021

\begin{abstract}
This paper uses the shooting and posting of Kuaishou short videos by young villagers in Wushi Village, Wushi Town, Huzhu Autonomous County, Qinghai Province, China as a case study, attempting to explore the cultural significance of the Kuaishou Short Video Social Network frequently used in our daily lives. The short videos of those young villagers not only show the overlapping of online and offline spaces in urban and rural areas, but also present another possibility of the coexistence between urban and rural cultures in the new era of Internet. Kuaishou has become a metaphor and a stage for the ambiguity and coexistence of urban and rural boundaries by virtue of the relative ease and availability of short video editing. The use of Kuaishou by young Monguor villagers is of great significance in addressing the traditional urban-rural dual economic structure.
\end{abstract}

Keywords Kuaishou short video social network · Youth · Urban-rural cultural linkage

\section{Introduction}

China's internet sector is growing at a staggering pace. According to the "White Paper of China's Internet Economy in 2017" released by China Internet Network Information Center, by November 2016, China became one of the world's largest Internet markets and the number of Internet users in China has reached 710

Guangxu Ji

jiguangx_43177984@qq.com

1 Journalism and Communication College of Guangdong University of Foreign Studies, Xiaoguwei, Panyu District, Guangzhou 510006, China 
million, ranking first in the world, equivalent to the total number of Internet users in India and the United States combined. ${ }^{1}$ The rapid growth of Internet access and the high penetration rates of mobile phones and other terminal devices have accelerated China's overall urbanization process. More importantly, internet access in rural areas has an major impact on local culture, social organization and overall social change. First of all, research on the subject has found that "technological empowerment" occupies a large space and has attracted the attention of many scholars (Zheng, 2014). The issue of "empowerment" is given considerable attention in China's rural development as well as the new urbanization transformation which China is constantly advocating. Topics within this transformation include: how the Internet empowers rural grassroots activities and changes the pattern of domination over capital and power in China's urbanization process; and the way in which the Internet allows rural areas to develop from the bottom up, integrates local resources autonomously, and contributes to local employment, commerce, and public service ( $\mathrm{Li}, 2016$ ). Second, research on rural development in the context of the Internet have focused on the "digital divide" and the differences between urban and rural development more in the previous research model of the urban-rural dual structure. By reviewing the relevant literature, DiMaggio and other researchers proposed that the development of the digital divide has gone through two stages: the digital divide caused by the differences in access opportunities and digital inequality due to the differences in the use of the Internet (DiMaggio et al., 2003). As China's internet access rate is growing year by year, it is clear that the "digital divide" has been transformed from past access opportunities to application differences, which has led to a further widening of the digital divide between urban and rural areas. ${ }^{2}$ How to transform unused, fragmented resources that do not match the development of the industrial age into competitive capital through the connectivity of the Internet based on a village's own foundation, and how to realize the development of equal rights between urban and rural areas. These will become key issues in future Chinese rural studies, where large territories remain uncharted.

From the short video content made on Kuaishou by young Monguor villagers in Qinghai, we can see that these users patch up and juxtapose local and urban culture to show cultural adoption strategies and logic that are unique to the Internet era, which works to blur the urban-rural dual economic structure and weaken the developing urban-rural power gap. As a matter of fact, young Monguor villagers' Kuaishou practices clearly reflect the diversity and complexity of China's urbanization process in the Internet age.

Kuaishou's predecessor, "GIF Kuaishou," was founded in March 2011. GIF Kuaishou was a mobile application created for making and sharing GIF pictures. In November 2012, Kuaishou was transformed from a mere tool into a short video

\footnotetext{
${ }^{1}$ This data comes from the China Internet Network Information Center, of which the website is: http:// www.cnnic.net.cn/ and the access time was January 16, 2018.

${ }^{2}$ The differences in access opportunities emphasize the regional differences in the inability to use the Internet due to the lack of communication infrastructure, while the differences in application emphasize the differences in obtaining effective information due to personal differences in Internet literacy under the condition of equal Internet access, and the differences in the ability to transform information into wealth.
} 
community, and became a platform for users to photograph, video and share their everyday lives. Moreover, users could achieve real-time interaction with fans through live streaming. Up to now, the app has already reached 700 million users, and the average of daily active users has surpassed 100 million.

The young people in Wushi Village downloaded the Kuaishou app on their mobile phones. From July to August 2017, the author conducted a one-month field survey in the village, focusing on young villagers' production and sharing of these short videos. I made a comprehensive record of the online video editing and sharing practices as well as the daily lives of the group. Anything in the article that does not clearly indicate the source comes from the above field survey.

Wushi Village is located in Huzhu Monguor Autonomous County, Qinghai Province. It is an authentic Monguor village where Monguor people make up over $90 \%$ of the population. There are 467 households and 1648 people in the village. The young people in the village had taken to using Kuaishou with particular enthusiasm. The author found that when not working, they would spend a lot of time watching short videos uploaded by users to this application. Meanwhile, they themselves learned to make and share various short videos by imitation. This discovery was unexpected by the author at the beginning of the survey. It is surprising that a video-sharing social networking service like Kuaishou could penetrate the lives of young people in minority villages in Western China and occupy most of their leisure time in such a short time. What made the author even more interested in carrying out this research was a young man named $\mathrm{Li}_{\text {Yongfu }}{ }^{3}$ in the village. When asked about his future career plan, he did not hesitate to blurt out, "to be an Internet celebrity and earn a great deal of money." What this study wanted to focus on and discuss was how these young villagers devoted themselves to the Internet by using mobile phones and Kuaishou, how the two distinct identities - "Internet celebrity" and "rural youth" - manifested themselves on these youths and interacted with each other, and how the online urbanization practices represented by Kuaishou's short video social networking service became a possibility for solving the traditional urban-rural dual economic structure.

\section{Methodology}

With the deepening of globalization, it was worth noticing that, besides the fact that the writing and presentation of non-mainstream culture needed to be studied and discussed, even the "culture right there" mentioned by Clifford Geert was increasingly difficult to find (Geertz, 1973). However, in the Internet society, with the increasing mobility of people and culture, the "field" of anthropology naturally had to move, and even began to be virtualized. To this end, Manuel Castells proposed to get rid of the existing constraints on fieldwork in the physical space and instead sought research breakthroughs from the "Ethnography of Networks" (Castells, 2000). The study of young people's production of Kuaishou short videos in Wushi Village used a combination of Internet observation and field survey. The

\footnotetext{
${ }^{3}$ After obtaining the consent of the interviewee, the interviewee's real name has been kept anonymous.
} 
combination of virtual and real field surveys not only complemented each other, but also made a more realistic and objective description of the research target.

\section{Results}

According to data from Kuaishou in 2017, the number of active daily users of the Kuaishou service had exceeded 100 million; the total number of registrations had exceeded 700 million; more than 10 million new videos were made every day. The young people in Wushi Village were typical representatives of these 700 million users. During the survey, with the consent of the interviewees, the author checked the mobile phones of several young people in the village and found that, in addition to being generally accepted by WeChat as a "national app," Kuaishou became the second-ranking app. For young people, Kuaishou was a brand-new world which owned another space parallel to daily life. They used Kuaishou to record their lives and believed that the short videos they created could be seen by the world. For them, Kuaishou helped eliminate their loneliness and alienation, and enhance their happiness. Kuaishou gave the grassroots the right to record, express and share through technical means. For these ordinary young people, Kuaishou had given them the opportunity to express their world views. The "grassroots perspective" gave ordinary people the right to free expression, which weakened the urbanrural dual economic structure that is deeply entrenched in Chinese countryside at present. Young people began to juxtapose urban and village cultures through their videos, so that the two coexisted in the same space. The urban and rural cultural linkage embodied in Kuaishou had a close relationship with Kuaishou's own labeling features. This article will go on to focus on the three aspects of Kuaishou as a video-sharing social network, namely recordability, inclusiveness, and technologydriven capacity.

\section{Recordability of Kuaishou: the subjective expression of urban and rural cultural linkage}

The village square of Wushi, which is the seat of the village committee, has the only free WIFI in the village. There were often young people squatting on the concrete platform of the square and staring at their mobile phone screens intently. Watching the short videos released by "Internet celebrities" on Kuaishou, every so often they exchanged comments with their friends around them. At first, I was unsure what these young villagers were staring at on their screens every day, supposing that they were just playing video games. Later, I discovered that they were enjoying folk songs performed by young girls dressed in folk costumes, and commenting on a youth from Northeast China eating a substantial seafood dinner. By my judgment, the youth in the latter video with a strong accent, live streaming himself eating seafood like a hungry wolf, was from Dalian. The young people in the village said they more or less did not understand what this Northeastern boy was saying, but they felt that this Internet celebrity, who they had been following for a long time, was particularly fantastic. When asked why they felt the boy was 
so fantastic and why they spent a lot of time and energy watching the live streams, one of them, Li Yongfu, said, "You see, he just sits in front of the camera and eats and drinks every day, and then so many fans follow and tip him! Every month, he will earn several thousand dollars. I desire to be a celebrity and make a lot of money."

Li Yongfu registered an account on Kuaishou a year ago and he would spend an hour or two on the application every day, mainly uploading videos, browsing recommendations, hitting the "like" button for his friends, reading comments, and following live streamers. Having watched the short videos uploaded by Li Yongfu, I found that most of the videos were about daily life, including religious activities, daily work, leisure party activities, and personal selfie short videos. I found that, vulgar and weird content, a large amount of which are circulated on the Internet to attract attention on live streaming, were not included in videos shared by the young people in Wushi village. Li Yongfu said that although they often watch the celebrities' live streaming on Kuaishou, they had their own limits as to what could be uploaded on Kuaishou. He said that he had been following Kuaishou for more than a year, and found that though videos featuring overeating, self-mutilation, and pornography on Kuaishou could receive attention very quickly, he didn't want to follow their example. He told me that he enjoyed sharing his daily life with online friends, and what he shared "must be real and must not be performed." He worked as a salesman in a mobile phone store in Xining, the capital city of Qinghai, and he also provided a post-sales repair service for customers. He said that when he was repairing a mobile phone, he would make a video to tell people how to avoid being cheated if they had to have their mobile phones repaired. After returning to the village, he would open Kuaishou and show the old villagers videos of people spinning the prayer wheel while chanting Buddhist scriptures around the white pagoda, and videos of him and his friends roasting potatoes in the forest while singing Hua'er (a folk song) and pop songs around the ash pit. When I was doing research in the village, he even invited me to cameo in his video at the interviewee's home, introduced to his fans what anthropology was and explained why the author had come to his village to conduct such a survey.

The pursuit of Kuaishou users in the village was to express their real lives in a subjective way. It was their desire to be able to express their ideas freely since they no longer wanted their lives and culture to "be expressed by others." Kuaishou gave them the power to record, to express and to broadcast these ideas through technical means. In this new space of expression, video was the best carrier of the subject's right to express themselves. Kuaishou presented a completely different world, with beauty and ugliness, good and evil, positivity and negativity, brightness and darkness, hope and despair. It was a "real, diverse and even a little bit problematic world," as Li Yongfu put it. The videos they posted were disorganized, without identifiable themes or patterns. These video journals kept track of the young villagers' lives, reflecting their mobility and ambiguity. The videos they posted were narcissistic self-portraits, in which they wore sunglasses and tights, and rode on motorcycles with cool poses, showing a strong taste for "countrified fashion." Sometimes they posted videos in which they wore traditional Monguor clothes to attend a ceremony or celebration. On May 7, 2018, Li Yongfu uploaded 
a video about the marriage of his Monguor friend on his Kuaishou app. In the video, they all wore Monguor clothes and sat in the groom's yard listening to the bride's uncle singing "Hua'er," a Monguor farewell song to the daughter about to marry. He dubbed in the video that he did not understand what these songs meant, and said that the uncle who sang in the video was one of the few middle-aged people in other villages who could still sing Hua'er. The intersection and overlapping display of urban and rural areas were clearly pronounced in Li Yongfu's video. Wandering between the two cultures, they neither fully identified with urban culture, nor deliberately exaggerated traditions, the result of which was a mixed cultural expression.

\section{The inclusiveness of Kuaishou as a short-video sharing platform: diverse ex- pressions of urban and rural cultural linkage}

Inclusiveness means to ensure that everyone has the equal opportunity to write their own records. Kuaishou allows every user to be recorded and does not discriminate in terms of one's figure and wealth. Therefore, everyone can be treated equally on Kuaishou. The young people in the village were enthusiastic about posting short videos on Kuaishou because their peasant origins did not hinder them from showing the world their understanding of life. After almost a year's observation, I was impressed by Kuaishou's decentralized nature. Everyone on the platform was given equal attention and traffic. Celebrities did not get more traffic; rather, it was those interesting ordinary people that received more attention. The reason why Li Yongfu was determined to be an Internet celebrity was that Kuaishou had pointed out for him a path of identity transition from a farmer to an Internet celebrity through his own efforts. Through the recommendation of Li Yongfu, I became acquainted with Li Yong, a young man who is regarded as the local "Internet celebrity." Li Yong was an early follower of Kuaishou and became the first live streamer in Wushi Village, having accumulated 300 fans rapidly through his adept social skills. With monthly live streaming and short videos posted on Kuaishou, Li Yong was able to earn about 300 yuan. Although this income was insignificant, it was a great incentive for other young people in the village to follow in Li Yong's footsteps and diligently run their own Kuaishou live streaming to make money. Inclusiveness gives ordinary people the opportunity to speak, thus bringing about a more diverse cultural presentation, which is the deepest impression left by Kuaishou. Every time I opened the Kuaishou app and reviewed the latest videos posted by Monguor villagers, I was overwhelmed by their authenticity and diversity.

The Internet is an ideal field for fostering diversity. Kuaishou offers these young people multiple opportunities for expression since a mobile phone and a Kuaishou account can allow them to freely express their diverse understandings of life. In their spare time, urban youth would usually order a cup of coffee and sit under the umbrella of Starbucks watching pedestrians come and go, or fly to a picturesque seaside, reading a novel by the writer they admire while wearing sunglasses. The young people in Wushi village, however, have their own way of understanding leisure. Because the cultural traditions of the Monguor people draw substantially 
from Tibetan culture, the Tibetans' Linka Festival (walking through the forest) has a profound impact on them. The young people in the village like to go to the woods together for picnics, singing while drinking beer. Sometimes they bring their own potatoes and light fires in the woods to roast potatoes. At this time, someone will take out their mobile phone, use the panorama mode to video everyone at the party, and share the video on Kuaishou with lively background music. These young people are the "silent majority." Without the Kuaishou platform, their lives would not be observed or perhaps even noticed by others. "Leisure" as we know it seems elitist, and in such a disparity in the power of speech, naturally people's understanding of life would become increasingly homogenized. This inclusive way of recording life allows viewers in different times and spaces to see a diverse and beautiful real world, one that includes people and things that have never appeared in their life before. On Kuaishou, urban and rural culture coexist in the same space. The elite, urban discourse that was once monolithic in the context of the Internet has begun to be replaced by more diverse discourses. Urban culture is no longer the only symbol of elite culture; rural culture appears and can be watched on Kuaishou more than ever. The power gap between the two cultures has been narrowed and the previous urban-rural dual economic structure has been blurred by free expression.

\section{Technology-driven capacity of Kuaishou: collective expression of rural culture}

At present, artificial intelligence (AI) technology has begun to be deeply integrated into the daily Internet practice of web users, and the basic core program in network technology is now quite developed. Currently most algorithms and information filtering techniques determine what users seem to be interested in based on their dynamic behaviors such as link clicks, text input, and online searches. That is, the online behavior of app and web users with similar backgrounds will be recorded and tagged in detail to infer their likes and dislikes. Kuaishou is no exception. All users' recommendations, likes, and follows will be recorded by the algorithm, and analyzed by powerful AI technology to "tag" different users. The videos that meet the users' taste will be recommended to them based on the accurately calculated tags. Therefore, it is not difficult to understand why, when users open Kuaishou, most people's reaction will be --"how could it be so vulgar." Vulgarity is a concept with a huge power gap embedded within it. It is the attitude and stance of cultural elites looking down upon other cultures. It shows urban culture's contempt for rural culture, as the former has long occupied the high ground of power. As a matter of fact, Kuaishou's vulgarity reflects the maladjustment of elite culture, which has long commanded the power of speech, when it coexists with rural culture. On previous Internet platforms, urban culture has occupied a dominant position; people have long been accustomed to a centralized communication paradigm and are familiar with the hierarchy between urban and rural cultures. They are so settled in the status quo that any change in order will bring them a strong sense of disorder and discomfort. Kuaishou happens to juxtapose rural culture with urban culture through grassroots recording and decentralized expression. At the same time, it uses AI algorithms to continuously recommend more rural cultural elements to the 
viewer, which challenges and shocks the viewer's previous understanding of the Internet. In anthropological terms, this is culture shock.

In fact, I also felt this shock when I first followed with interest the Kuaishou videos of those young people from Wushi village. They deliberately made their videos look more fashionable, and they used sentimental and low-pitched pop music to create a lonely, melancholy scene. Besides, they also liked to add a text to their videos, such as "how can I be ruthless if you have a heart," and "I got drunk for you though I never drank before." The young people said that they learned these methods of video shooting and processing from other users' Kuaishou videos. They felt that such videos were cool and in line with their understanding of fashion. When browsing Kuaishou with these young villagers, I found that what they did most often on Kuaishou was "glance over recommendations, like each other's content, read comments and follow other users." These four dynamic, practical behaviors were the most applicable for the computing program to record user preferences and "tag" the user. Continued observations proved that browsing recommendations took them the longest time as they often spent an hour browsing videos recommended by the algorithm. After discovering an interesting user, they would be recommended to follow each other, so that the similarities among their followers would be strengthened. Thanks to the free expression and transmission as well as the AI algorithms on Kuaishou, young villagers became more and more interested in the rurality of the platform, and they found that posting videos with rural elements on Kuaishou would not be despised and blocked. Instead, they received more encouragement and likes. This greatly enhanced their feeling of happiness and confidence in rural culture. Meanwhile, their motivation to make and post videos on Kuaishou increased unprecedentedly with the profits they were able to gain from the platform. The videos shot by the youths became an important means for me to study the rural culture of today. They made videos of festivals, both big and small, as well as weddings, funeral ceremonies, and the daily work of the villagers, including even newly harvested potatoes and broad beans.

\section{Discussions}

Throughout the history of China, rural markets were well developed, with unobstructed space and freely flowing information, population movements and commercial information networks overlapped with the real communities of rural selfgovernment, and urban and rural areas developed in harmony. After the Opium War (1839-1842), factory industries entered China and industrial production emptied the countryside of its labor force, leading to the marginalisation of the countryside and an intensification of the urban-rural divide. Urban development siphoned off rural resources, resulting in a serious development imbalance between urban and rural areas. The rural culture and customs were disappearing at an accelerating rate because they hindered large-scale industrial production, whereas people and land were being brought together in cities as a means of production. As far as cities were concerned, useful things from the countryside were used, and those that were 
useless were discarded. But now, the quick rise of the decentralized Kuaishou app naturally integrates with the vast number of peasants in China, empowers individuals, and brings about the integration and reconstruction of urban and rural culture.

\section{Strategies for urban and rural cultural identity on Kuaishou}

The young people who shot videos were a group of people who rapidly socialized by continuously accepting and absorbing different cultural elements. They combine strong abilities to learn and imitate with the needs for strong self-shaping and rolebuilding, which are human instincts, and they have to constantly try and make adjustments at this stage of rapid socialization in order to define their own roles in the end. Erik Erikson pointed out that during adolescence there is a legal period of delay before the assumption of adult obligations, which is the period most prone to identity crisis or confusion (Erikson and Sun, 1998). During this period, teenagers begin to pay attention to self-identity and distinguish the boundary between the self and others in real life to determine who they are. Digital media in the Internet age allows rural youth to easily link to the world through various channels with their minds brimming over with explosively heterogeneous pieces of information. The Internet has brought about a space where rural and urban culture are juxtaposed. These teenagers have begun to have selective difficulty in knowing and expressing themselves. This confused, liminal phase has caused some of them to start juxtaposing offline space with online space. They rely on the overlap to create a "self" and an "avatar" to alleviate the obstacles in identity construction caused by their confusion. The "self" mainly solves the problem of identity shaping and role construction in offline space. They will conduct physical and behavioral discipline training to obtain self-identity in accordance with the established social norms for young people. The "avatar" mainly facilitates their attempts to realize the roles in online life on platforms like Kuaishou, breaking through the prescribed roles preset by the offline society for young people, digging out "multi-oriented selves," and having them expressed through various texts on the Internet. Without a doubt, there is no clear and insurmountable boundary between these two identities. When watching the young villagers' Kuaishou videos, I found that they also put their "selves" in daily life on the Internet, including colorful ethnic festivals, wedding and funeral ceremonies, farm work and life and other clips. The rural "self" even became a unique label that they have established on Kuaishou to distinguish themselves from other users. Monguor identity and its accompanying cultural elements became an important resource for them to accumulate fans on Kuaishou and achieve social realization, all the while strengthening their identification with rural culture.

In addition to demonstrating their connection to people with similarities and gaining a sense of belonging to a certain group, any person who completes the process of identity shaping and identification needs to classify and identify with others. As a social feature and attribute, identity is a common understanding of a certain group. It emphasizes the similarity between members, and at the same time the members also take pride in sharing a particular set of attributes and characteristics. The youth in Wushi Village followed each other on Kuaishou, became friends, 
and shared videos posted by similar types of celebrities. In their offline life, they even visited the village in groups through various types of organized activities. I found that the young people in the village were similar in terms of their fashion sense, leisure preferences, and even the types of work when they chose to go out to work. For example, young men in the village generally like to wear snow-white shirts, a brightly colored jacket, skinny tapered jeans, and a pair of light sports shoes. They prefer gathering in the village square in their free time, sharing short videos on Kuaishou with free $\mathrm{Wi}-\mathrm{Fi}$, and making comments on the videos from time to time. Through such ceremonial attire and daily life, they could easily develop their group subculture in a group setting, while generating a strong sense of group identity and pride.

The existence and maintenance of the quasi-urban identity of the online "avatar" is realized by the production and sharing of the above-mentioned internal "common culture." Members imitate, improve and innovate the shape and behavior of "avatars" to establish the image of urban people in their mind; through imitating other group members and broadcasting themselves, a set of shared performative experiences and cultural symbols is solidified, based on which the cultural style of the online "avatar" is established. Although this style was not as strong and attractive as the "smart" culture studied by previous scholars, the online practice of young people in Wushi Village did indeed present a kind of cultural identity and social positioning expressed through negotiation and sharing. These young people united their individual imagination of themselves (the "self") with the imagination of urban culture (the "avatar"), and created their own cognition and understanding of urban culture through the videos constantly posted on Kuaishou.

\section{Elimination of the gap between urban and rural cultural power on Kuaishou}

Paola Voci proposed a concept while studying mobile videos in China, that is, "lightness" (Voci, 2010). "Lightness," which means worthlessness to outsiders, is the intuitive impression that others outside the culture have of the videos produced and reposted by these young people. This is an act of "tagging," a reaction to a culture shock in the same way as the perception that Kuaishou video is "vulgar." In the beginning, most people who came to know Kuaishou were unable to understand why those users wanted to behave so inappropriately in their videos. Perhaps they had thought that these users were "selling self-esteem to get attention." However, when people learned that these users' aspiration was "to be an Internet celebrity and make a fortune" and"to open a supermarket of their own and make ends meet in their hometown," they would realize it was these numerous "lightnesses" that constituted the meaning of life and culture. When we look at these videos from the perspective of showing daily life and telling stories, lightness is weight. "Lightness" and "weight" in the context of Kuaishou video are a pair of concepts that encompass a power relationship, reflecting the vastly different discourses between urban and rural culture. By presenting these videos in front of the eyes of urban people through the Internet and giving them equal rights of display, Kuaishou offered those young people who cannot surpass the urban-rural dual economic structure in real life a platform to show their culture with confidence. These videos 
represented the young villagers' imitation of the world outside the village, and, in a deeper sense, their expectation of a breakthrough in the traditional dual values of the local culture with which they had been born. Young people living in the countryside had been constantly dreaming of breaking through social boundaries and reaching the urban world where resources abound. Their expressions on Kuaishou, seeking for followers and praise (likes), were essentially an attempt to resist the reality of China's urban-rural divide. They wanted to identify with the mainstream urban culture, and Kuaishou became a way for them to get close to the mainstream culture by presenting the rural culture, and eventually to be accepted by it. In reality, the dual structure of Chinese society discouraged them, and they were constantly rejected and despised by elite culture. They wore cheap imitation designer clothes, used OPPO and VIVO mobile phones, and uploaded staged photos and photoshopped pictures, trying their best to get closer to urban culture. However, they were ruthlessly ridiculed by urban people. For them, Kuaishou was an ideal place to escape to and dissolve the urban-rural dual economic structure, where they could show their "countrified fashion" and various other aspects of rural life. As a social platform focusing on documenting the daily lives of ordinary people, Kuaishou has no obvious elite cultural orientation. The diversity and inclusiveness of the platform allowed urban and rural culture to coexist and merge well. On Kuaishou, the Internet stimulated urban and rural cultural consumption and reshaped the urban and rural fabric. Thanks to the interaction of urban and rural culture on the Internet, these young people were no longer surrounded by the rules and moral derogation from elite culture, nor did they need to have a high level of ability to justify and clarify their own culture. On Kuaishou, they experienced the possibility of the coexistence and linkage of urban and rural culture.

\section{Diversified presentation on Kuaishou}

According to the anthropologist Arjun Appadurai, electronic media provides new resources and rules for constructing imagined selves and worlds, marking and reconstructing a wider field as an experimental resource for constructing selves. This field is accessible to all people in all societies (Appadurai and Liu, 2012). Young people in Wushi Village constantly drew resources through WeChat, Kuaishou and other social media, and used these resources to construct their own imagination and perception of the outside world. Electronic media offered these young people the possibility to write the scripts of their lives, filling them with the glamor of a celebrity and the fantasy of a movie script. Yet, at the same time, these possibilities had a high degree of credibility, since those that were being imitated could be seen live in the flesh on Kuaishou's live streaming, making content much more credible. Electronic media, represented by Kuaishou, with their richness of form and speediness of transmission, provide users with the resources for selfimagination as an everyday social project.

As an open platform, Kuaishou produces a large volume of videos every day. These videos could be used as a resource by young people in the village to build their own understanding of the outside world. It was also because of the wide range of resources and the platform's tolerance for video-recorded content that a 
large number of videos with rural elements could be found on Kuaishou. That is not the extent of Kuaishou's content, however. Kuaishou was like a big stage, upon which all ordinary people had the opportunity to stand. In this way, people saw a lot of content that fell somewhere between urban and rural culture, such as a delivery boy in the city, an apprentice in the barber shop, or a worker on an assembly line for mobile phone production. They were all migrant workers from the countryside who, as the silent majority, had no opportunity or stage to show themselves in the city. The strong urban-rural dual economic structure impacted their urban experience, and they were overwhelmed with the sense of isolation. On Kuaishou, these people could indeed become "interesting ordinary people" by their own display and efforts, attract people's attention, and become celebrities on the Internet. The diversified characteristics of Kuaishou reflected equality and diversity, where urban and rural cultures coexisted, reflecting the spacial trend towards "non-ruralisation of the countryside and decentralisation of the city." The young people in Wushi Village made full use of videos on Kuaishou to show what they thought was fashionable, a cultural mosaic that was rooted in the countryside but also transcended it. Other videos on the platform, such as the aforementioned young people in the grassroots working hard in the cities, showed in their videos how they used Kuaishou to get rid of the feeling of exclusion and isolation in real life.

These videos revealed these young men's yearning for and imitation of urban life, and their use and transformation of their own culture. From the perspective of social progress, the coexistence of the two cultures as displayed on the Kuaishou platform represented a process occurring between the rural and urban cultures. In this process, there was no distinction or explicit power relationship between the mainstream and non-mainstream. Kuaishou blurred the boundaries of dualism in real life so as to provide a fresh way of looking at the world.

\section{Conclusion}

The emergence of Kuaishou enabled these young Monguor villagers to enter into a new scene, one in which urban and rural areas were merged and melded, in which online and offline spaces overlapped. With the help of mobile Internet, young people in the villages entered a space where two cultures coexisted, where the difference between urban and rural areas was no longer a barrier to their identity; where they were not discriminated against because of their rural identity; and where they could present more freely what they understood to be urban culture and fashion. They experienced a new way of connecting with the outside world and a new stage for display. The linkage and coexistence of two cultures was what was missing in today's urbanization studies, in which the imbalance of developmental power between urban and rural areas had made the city the dominant power in the process of rural urbanization, and rural culture had been devoured. Urbanization that occurred offline reflected the competing relationship between urban and rural areas, but online it was a different story. The development of the Internet provided a new interpretation of this process. Kuaishou became a platform for this area of ambiguity, allowing those rural youths who were unable to show their knowledge 
on Zhihu or their good looks on major live streaming platforms, but who were nevertheless enthusiastic and passionate for "a performance stage" to come together. Through their videos, they showed their new feelings about the urbanization of today, the overlapping of urban and rural, online and offline spaces, and another possibility of coexistence between urban and rural culture in the new Internet era. Kuaishou became a metaphor and a stage for the ambiguity and coexistence of urban and rural boundaries, using a relatively easy and accessible portable video format. Diversity, of course, obscured the dichotomy between urban and rural areas to a certain extent, and brought about the possibility of cultural integration between urban and rural areas. However, pluralism was also a double-edged sword, and pluralism without institutional constraints would lead to disorder and the unchecked pursuit of novelty. On Kuaishou there were ordinary yet beautiful stories of ordinary people's lives, but there were also acts of self-mutilation, violence and sex. These contents strayed into the fringes, generating huge amounts of traffic as well as huge amounts of negative social value. Li Yongfu used a metaphor to explain why he didn't pursue novelty. He said:

"Kuaishou is like a rapeseed field. Everyone works hard to cultivate their own land, waiting for the production of rapeseed to increase. Some people use chemical fertilizers while other people use farmyard fertilizers. While excessive use of chemical fertilizers can increase production in a short time and make extra income, this will devastate the land and such development will be impossible to sustain. Likewise, although the output of farmyard manure is not high, it can maintain the fertility of the land and help you achieve sustainable development. The same is true for Kuaishou. Those weird videos are chemical fertilizers and don't have any stamina."

On an ideal regulatory basis, the development of Kuaishou will also be instrumental to sociological and anthropological field surveys. The application is a window through which social development can be seen, and the invisible majority's daily life can be rendered visible. The users of Kuaishou are ordinary people, and it presents viewers with the real, diverse and even problematic world in a down-to-earth way, which is, after all, the life we have been living all along.

Acknowledgements Not applicable.

Author's contributions The author read and approved the final manuscript

Funding Not applicable.

Availability of data and materials Not Applicable.

\section{Declarations}

Ethics approval and consent to participate The study protocol was approved by the Research and Ethics committee of Journalism and Communication College, Guangdong University of Foreign Studies. Before the commencement of the study, the participants were informed and explained the objectives of the study and their consent were taken. 
Consent for publication I accept the copyright regulation of your journal and authorize your journal to publish my paper, if possible.

Competing interests The author has no conflict of interest.

Open Access This article is licensed under a Creative Commons Attribution 4.0 International License, which permits use, sharing, adaptation, distribution and reproduction in any medium or format, as long as you give appropriate credit to the original author(s) and the source, provide a link to the Creative Commons licence, and indicate if changes were made. The images or other third party material in this article are included in the article's Creative Commons licence, unless indicated otherwise in a credit line to the material. If material is not included in the article's Creative Commons licence and your intended use is not permitted by statutory regulation or exceeds the permitted use, you will need to obtain permission directly from the copyright holder. To view a copy of this licence, visit http:// creativecommons.org/licenses/by/4.0/.

\section{References}

Appadurai, Arjun., Liu, Ran (刘申), trans. 2012. Modernity At Large: Cultural Dimensions of Globalization (《消散的现代性: 全球化的文化维度》). Shanghai: SDX Joint Publishing (上海三联书店).

Castells, M. 2000. The information age: Economy, society, and culture. Volume 1: The rise of the network society. Boston: Blackwell.

DiMaggio, Paul, et al. 2003. "From unequal access to differentiated use: A literature review and agenda for research on digital inequality," report prepared for the Russell Sage Foundation, working paper 29. Princeton: Princeton University, Center for Arts and Cultural Policy Studies.

Erikson, Erik H., Sun, Mingzhi (孙名之), trans. 1998. Identity: Youth and Crisis (《同一性:青少年与危机》), 117-18. Hangzhou: Zhejiang Education Publishing House (杭州:浙江教育出版社).

Geertz, C. 1973. The interpretation of cultures: Selected essays, 10. New York: Basic Books.

$\mathrm{Li}, \mathrm{Zi}$ (李孜). 2016. Rise of E-commerce in Rural China: From County E-commerce Service to Online Urbanization (《农村电商崛起: 从县域电商服务到在线城镇化》), 2. Beijing: Publishing House of Electronics Industry (北京:电子工业出版社).

Voci, Paola. 2010. China on video: Smaller-screen realities. London: Routledge.

Zheng, Yongnian (郑永年). 2014. Technological Empowerment: The Internet, State and Society in China (《技术赋权:中国的互联网、国家与社会》). Beijing: People's Oriental Press (北京:东方出版社).

\section{Comments}

Publisher's Note Springer Nature remains neutral with regard to jurisdictional claims in published maps and institutional affiliations. 